\title{
Pemaknaan dan Konsekuensi Budaya Tato Pada Suku Dayak
}

\author{
Elok Feni Sia \\ Magister Psikologi Sains, Fakultas Psikologi, Universitas Surabaya \\ elokfenisia01@gmail.com \\ Taufik Akbar Rizqi Yunanto \\ Magister Psikologi Sains, Fakultas Psikologi, Universitas Surabaya \\ taufik_yunanto@staff.ubaya.ac.id
}

\begin{abstract}
Dayak Tribe were originally from immigrants from the Yunnan region of southern China and traveled on the island of Borneo. Dayak tribe itself has a culture of signs or symbols where each motif and placement of tattoo have different meanings and can also be done carelessly. According to the belief that black tattoo will turn into a pathway to eternity after they die, the tattoo is a spiritual aspect and inheritance that is in accordance with the Dayak tribe and tattoo can also symbolize high identity and social status. This goal is to find out the meaning and understanding of tattoo culture in Dayak tribe. According to Throndike, behavioristic learning theory emphasizes consideration in terms of (Readiness Law), (Exercise Law), (Influence Law). A pleasant consequence would be to improve tattooing behavior, if the individual is ready to meet the procedures and prerequisites for tattooing the individual will continue to train him then receive the pleasant and acceptable because he can tattoo.
\end{abstract}

Keywords: dayak tribe; tatto mean; consequences.

\begin{abstract}
Abstrak
Suku Dayak dulunya merupakan keturunan dari imigran yang berasal dari wilayah Yunnan di Cina Selatan dan mengembara di Pulau Kalimantan. Suku Dayak sendiri memiliki budaya tato, tanda atau simbol dimana setiap motif dan penempatan tato memiliki arti yang berbeda dan juga tidak boleh dilakukan secara sembarangan. Menurut kepercayaan tato yang berwarna hitam akan berubah menjadi penerang jalan menuju keabadian setelah mereka mati, tato tersebut merupakan aspek spritual dan warisan yang suci bagi masyarakat suku dayak serta tato juga dapat melambangkan identitas dan status sosial yang tinggi. Tujuan penelitian untuk mengetahui pemaknaan dan konsekuensi budaya tato pada Suku Dayak. Menurut Throndike teori belajar behavioristik menekankan pada konsekuensi ditinjau dari (Law of Readiness), (Law of Exercise), (Law of Effect). Konsekuensi yang menyenangkan akan memperkuat perilaku menato, jika individu siap memenuhi prosedur dan prasyarat untuk menato individu akan
\end{abstract}


melatihnya terus kemudian menerima akibat yang menyenangkan dan merasa puas karena dapat mentato.

Kata kunci: suku dayak; makna tato; konsekuensi.

\section{Pendahuluan}

Suku dayak merupakan keturunan dari imigran yang berasal dari wilayah Yunnan di Cina Selatan kemudian dari situlah kelompok-kelompok mengembara memasuki pulau-pulau di Indonesia dan Kalimantan (Coomans, 1987). Suku dayak juga memiliki tradisi budaya seperti upacara adat hasil panen, upacara kematian, upacara perkawinan, tari-tarian, memanjangkan daun telinga, festival pemuda, dan tato (Maunati, 2004). Seni tato khas suku dayak merupakan suatu tanda kebudayaan yang sudah ada sejak zaman dahulu dan sangat bernilai serta memiliki makna tersendiri oleh sebagian besar suku dayak asli. Tato atau seni rajah tubuh, dapat digunakan sebagai simbol atau penanda dalam tubuh manusia, dan sebagai media komunikasi bahasa non verbal bagi masyarakat suku dayak adalah tanda atau sebagai simbol yang dapat di gambar, berbentuk tulis-tulisan, lukisan, foto, atau bahkan tema yang dapat dituangkan dibagian atas kulit menjadi sebuah karya seni dengan menggunakan alat yaitu jarum dan zat warna untuk memasukannya kedalam tubuh (Karyadi, 2017). Hiasan tato pada tubuh tersebut semata-mata bukan untuk gaya, tetapi bagi masyarakat suku dayak tato yang dibuat pada tubuh dapat bercerita mengenai pengalaman-pengalaman atau realitas yang ingin didapat oleh individu yang memakainya (Fakhri \& Kahija, 2015).

Bagi masyarakat Suku Dayak budaya tato merupakan suatu hal yang sakral dan luhur artinya tidak boleh dilepas atau bahkan dihapuskan dari adat istiadat mereka, budaya tato juga diturunkan dari generasi ke generasi sebagai warisan yang suci karena itu tidak boleh dibuat dengan sembarangan (Coomans 1987). Menurut kepercayaan tato yang berwarna hitam akan berubah menjadi penerang jalan menuju keabadian setelah mereka mati. Tato tersebut merupakan aspek spritual, keagamaan, melambangkan status sosial seseorang dalam masyarakat, juga penghargaan suku terhadap kemampuan seseorang, serta banyaknya tato menggambarkan orang tersebut sudah kuat mengembara dan 
pemiliknya sudah banyak mengunjungi banyak kampung. Itulah yang menyebabkan adanya peraturan dalam pemilihan tato baik gambar maupun penempatan tato.

Tato juga dapat diberikan kepada keluarga kerajaan atau golongan bangsawan lazimnya motif tato yang digunakan adalah motif burung Enggang, yakni burung endemik Kalimantan yang dikeramatkan. Ada pula tato yang dibuat di bagian paha, bagi perempuan Dayak yang memiliki tato dibagian paha menandakan status sosial yang sangat tinggi dan biasanya dilengkapi dengan gelang dibagian bawah betis. Selain dibutuhkan niat, calon pemilik tato juga harus menahan rasa sakit saat jarum menembus kulit karena itu yang ingin membuat tato tidak boleh setengah-setengah (Pradita, 2013).

Namun kini, seiring perkembangan zaman di era modern makna dari tato tersebut bergeser dan bukan menjadi sesuatu yang suci, dan sakral lagi dikarenakan saat ini golongan yang lebih muda tidak lagi melakukan aktivitasaktivitas yang sama seperti mentato tubuh dengan yang dilakukan oleh kelompok yang lebih tua sebelumnya karena lingkungan dan pola berpikir mereka yang berbeda. Selain itu juga di era sekarang untuk melamar pekerjaan ada beberapa instansi khususnya Calon Pegawai Negeri Sipil (CPNS) yang memiliki syarat tidak diperbolehkan memiliki tato di tubuh hal tersebut yang membuat golongan masyarakat dayak yang lebih muda memilih untuk tidak mentato tubunya (Karyadi, 2017) sedangkan pada kelompok yang lebih tua sebelumnya menganggap bahwa membuat tato pada tubuh adalah sesuatu yang sakral dan budaya yang sudah diwariskan dari nenek moyang.

Fenomena yang terjadi saat ini juga pemerintah indonesia menggenjot pertumbuhan pariwisata khususnya di wilayah provinsi Kalimantan Timur dan dinas pariwisata serta pemerintah daerah (Pemda) Kalimantan Timur lebih mempromosikan kebudayaan dayak sebagai sebuah daya tarik wisata yang penting (Maunati, 2004). Oleh karena itu berdasarkan gambaran di atas, tentu menjadi menarik untuk menggali pemaknaan dan konsekuensi budaya tato pada suku dayak. Tujuan dalam penulisan ini adalah untuk mengetahui pemaknaan dan konsekuensi budaya tato pada masyarakat Suku Dayak dan manfaat dari penulisan 
ini diharapkan mampu dijadikan sebagai rujukan kepada masyarakat yang belum mengetahui makna dan konsekuensi tato pada masyarakat tradisional suku dayak dan kemudian dapat melestarikan kearifan lokal yang hampir punah.

\section{Pembahasan}

Pada umumnya suku dayak terbagi dalam enam kelompok besar yaitu, Kenyah Kayan dan Bahau yang mendiami daerah Kalimantan Timur, Ot-Danum yang umunnya mendiami daerah Kalimantan Tengah, Kelematan yang mendiami daerah Kalimantan Barat, Heban yang mendiami daerah Malaysia Timur, bagian Serawak, Murut yang mendiami daerah Malysia Timur, bagian Sabah dan bagian Utara Kalimantan Timur, dan Punan atau suku-suku yang mengembara dipedalaman Kalimantan. Kemudian pada kelompok besar ini didalamnya terbagi lagi menjadi sub-sub kelompok kecil (Coomans M 1987).

Tato yang berkembang pada masyarakat dayak dibuat dalam beragam motif ada yang seperti bentuk wajah seseorang, bunga, binatang, huruf, atau motif-motif lainnya dan setiap motif memiliki makna yang berbeda-beda. Misalnya, tato motif song irang atau tunas bambu oleh perempuan Dayak Bahau. Tato tersebut menyerupai motif-motif song irang atau tunas bambu, warna tato seperti kehijauan tua cenderung kehitaman karena dibuat dengan sari daundaunan. Jenis dan bentuknya menyerupai ukiran motif song irang atau tunas bambu yang melingkar di seluruh pergelangan tangan hingga telapak tangan. Penempatannya pun hanya di sekitar pergelangan tangan, namun ada pula tato yang dibuat di bagian paha. Bagi perempuan Dayak Bahau memiliki tato dibagian paha status sosialnya sangat tinggi dan biasanya dilengkapi gelang di bagian bawah betis. Masyarakat menganggap tato sebagai suatu identitas menurut Fromm (dalam Irawan, 2015) Identitas ialah kebutuhan untuk setiap manusia agar dapat menunjukan eksistensinya ditengah-tengah masyarakat yang lain. Seseorang yang sedang mencari identitasnya adalah seseorang yang ingin mengetahui dirinya dimasa mendatang bahwa mereka bagian dari masyarakat Suku Dayak.

Seseorang yang mentato tubuhnya juga tidak lepas dari namanya konsekuensi, menurut Throndike (dalam Irawan, 2015) teori belajar behavioristik 
menekankan pada konsekuensi ditinjau dari (Law of Readiness), (Law of Exercise), (Law of Effect). Dimana pada tahap (Law of readiness) menato tubuh adalah suatu yang menyenangkan ketika seseorang tersebut sudah siap untuk mentato tubuh hal itu akan membuatnya menjadi menyenangkan dan seseorang tersebut merasa terpuaskan, karena tidak sembarang orang yang dapat menato tubuhnya kecuali seseorang yang sudah memenuhi proses dan syarat adat yang sudah ditentukan oleh masyarakat Suku Dayak itu sendiri dan hal itu menjadi suatu penghargaan bagi individu yang sudah melakukannya. Kemudian ketika seseorang sudah melakukan tahapan tadi seseorang akan berusaha terus berlatih agar dapat mentato tubuh selanjutnya lagi dengan bentuk dan motif yang berbeda (Law of exercise). Ketika dimana seseorang tidak akan mentato tubuhnya lagi karena tidak adanya law of readiness dan law of exercise individu menganggap bahwa tato bukan suatu yang menyenangkan tetapi suatu yang menjengkelkan karena menato tubuh harus menahan rasa sakit yang begitu luar biasa.

Pada kaum yang lebih tua dahulunya menganggap tato sebagai suatu yang sakral dan menjadi jalan penerang mereka setelah kematian, dan menandakan sebagai suatu identitas sosial mereka tetapi ada pergeseran makna di era modern saat ini pada kelompok-kelompok masyarakat Suku Dayak yang lebih muda menganggap tato adalah sebagai warisan budaya yang menjadi suatu peninggalan nenek moyang yang mana sebagaimana mestinya menjadi kearifan lokal pada budaya di daerah Kalimantan. Lumintang (2015) perubahan masyarakat merupakan suatu proses yang akan terus menerus terjadi tetapi perubahan masyarakat yang satu dengan masyarakat yang lain tidak selalu sama. Soekanto (dalam Lumintang, 2015) menyatakan bahwa faktor perubahan sosial dalam masyarakat dikarenakan bertambah atau berkurangnya penduduk, adanya penemuan baru, pertentangan dalam masyarakat, dan revolusi dari masyarakat. Dalam hal ini masyarakat Suku Dayak pada kelompok yang lebih muda mengalami perubahan sosial tersebut salah satunya mengalami pertentangan dalam masyarakat di era modern saat ini jika menggunakan tato.

Menurut hasil penelitian Juniarto (2017) kelompok kaum muda memiliki kekahwatiran terkait masalah pekerjaan merasa takut nanti kesulitan dalam 
mencari pekerjaan dan memiliki tanggung jawab sosial terhadap anggapan negatif terhadap tato secara umum, konsekuensi akan di cap sebagai anak bandel oleh lingkungannya. Di era modern saat ini juga banyak masyarakat yang menggunakan tato sebagai bentuk kesenian tanpa mengetahui makna sesungguhnya sehingga ada pergeseran makna tato di era modern saat ini.

\section{Kesimpulan}

Kesimpulan dalam penelitian ini bahwa budaya tato pada Suku Dayak merupakan suatu identitas yang suci dan sakral serta sebagai penerang jalan menuju keabadian setelah mereka mati. Tato pada tubuh suku dayak tidak boleh dibuat sembarangan karena setiap motif dan penempatannya memiliki makna dan arti tersendiri. Konsekuensi yang dialami pada Suku Dayak akhirnya menyebabkan (Law of readiness) dimana menato tubuh adalah suatu yang menyenangkan ketika seseorang tersebut sudah siap untuk menato tubuh hal itu akan membuatnya menjadi menyenangkan dan akan terus dilakukan berulangulang sehingga kemudian dapat menato dengan motif yang berbeda lagi di tubuhnya.

Tetapi dengan bergesernya zaman di era modern ini budaya tato pada suku dayak mulai berkurang dikarenakan kelompok muda memiliki cara berpikir yang berbeda dengan kelompok sebelumnya dan ada pergeseran makna pada budaya tato itu sendiri serta kelompok muda memiliki kekahwatiran terkait masalah pekerjaan merasa takut nanti kesulitan dalam mencari pekerjaan dan memiliki tanggung jawab sosial terhadap anggapan negatif terhadap tato secara umum serta konsekuensi akan di cap sebagai anak bandel oleh lingkungannya.

\section{DAFTAR PUSTAKA}

Coomans, M. (1987). Manusia Daya: Dahulu, Sekarang, Masa Depan. Jakarta: Pt Gramedia

Dr. Maunati, Y. (2004). Identitas Dayak. Yokyak Arta: Lkis

Driyanti, R. (2011). Makna Simbol Tato Bagi Manusia Dayak Dalam Kajian Hermeneutika Paul Ricoeur. Tesis. Universitas Indonesia 
Fakhri \& Kahija. (2015) Menelusuri Kehidupan Pantang Iban : Gambaran Psikologis Manusia Berbudaya Tato Sebuah Interpretative Phenomenlogical Analysis. Jurnal Empati. Universitas Diponegoro.

Irawan, N.E. (2015). Pemikiran Tokoh-Tokoh Psikologi Dari Klasis Sampai Modern. Yogyakarta: Ircisod

Juniart, G.D. (2017). Persepsi Mahasiswa Dayak Kalimantan Barat Di Yogyakarta Terhadap Tato Motif Tradisional Dayak Terkait Dengan Identitas Sosial. Skripsi. Universitas Sanata Dharma. Yogyakarta

Karyadi, D.R. (2017). Eksistensi Kearifan Lokal Tato Masyarakat Suku Dayak Iban Di Provinsi Kalimantan Barat Setelah Berlakunya Peraturan Jaksa Agung Republika Indonesia Nomor Per-048/A/J.A/12/2011 Tentang Pengadaan Pegawai Negeri Sipil Kejaksaan Republika Indonesia. Jurnal Universitas Atma Jaya Yogyakarta.

Lumintang, J. (2015). Pengaruh Perubahan Sosial Terhadap Kemajuan Pembangunan Masyarakat Di Desa Tara-Tara 1. Journal Acta Diurna Vol Iv. No 2.

Pradita, E.M. (2013). Tato Sebagai Sebuah Media Komunikasi Non Verbal Suku Dayak Bahau. Jurnal Universitas Mulawarman. 